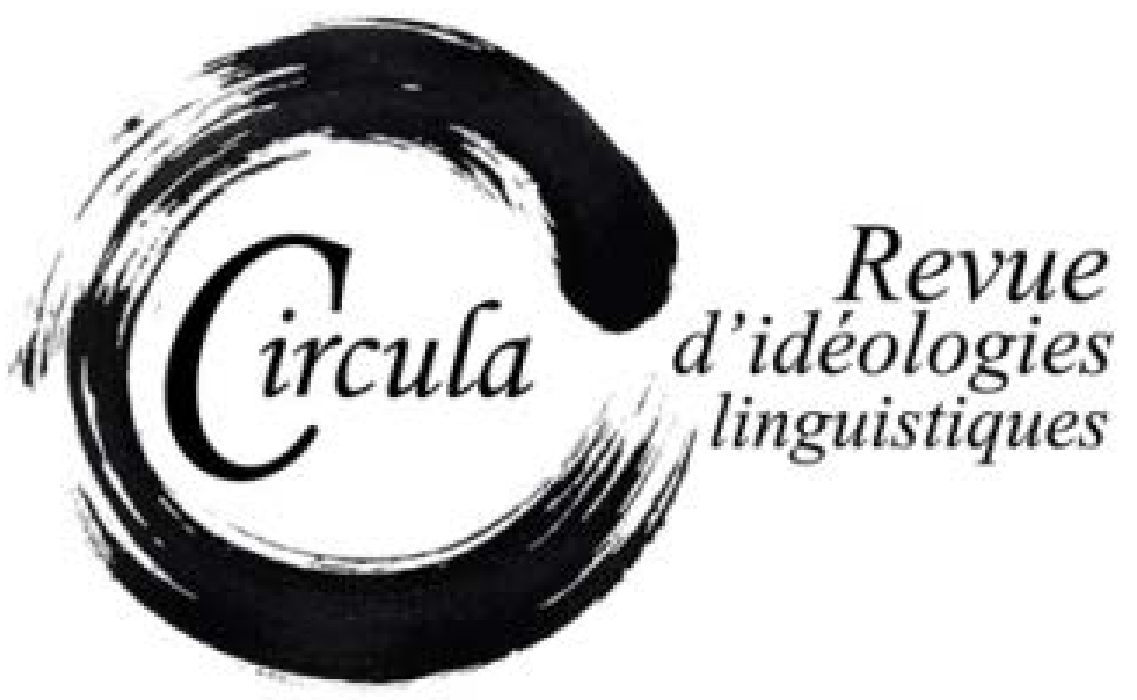

TITRE: SOBRE EL CONCEPTO “IDEOLOGÍA” Y SU REPERCUSIÓN EN LA EPISTEMOLOGÍA LINGÜÍSTICA Auteur(s): María Luisa Calero Vaquera, Universidad de Córdoba

Revue: CiRCula, numÉRO 8 - IDEOLOGÍAS EN OBRAS SOBRE LA LENGUA ESPAÑOLA (SS. XV-XX)

PAGES: $6-29$

ISSN: 2369-6761

Directeurs: : Francisco Escudero Paniagua, Carlos Villanueva García, Carmen Quijada Van DEN BERGHE, José Jesús Gómez AsEnCIO

URI: HTTP://HDL.HANDLE.NET/11143/15549

DOI: HTTPS://DOI.ORG/10.17118/11143/15549 


\title{
Sobre el concepto "ideología" y su repercusión en la epistemología lingüística
}

\author{
María Luisa Calero Vaquera, Universidad de Córdoba \\ mlcalero@uco.es
}

\begin{abstract}
Resumen: Se aborda aquí la repercusión que la ideología, como filtro que configura nuestra mirada del mundo, ha tenido en los últimos tiempos en el discurso lingüístico que se construye sobre el propio discurso (metadiscurso). A partir de la propuesta de Pérez Hernández (2000) de una nueva subdisciplina lingüística (etnolexicografía) que abarcaría el estudio de los diccionarios como textos que reflejan una visión ideológica del mundo, proponemos por nuestra parte la creación de dos subdisciplinas paralelas: la etnogramática y la etnortografía, las cuales, también integradas en el marco de la Glotopolítica, se ocuparían respectivamente de analizar el modo como se refleja la ideología en los textos de gramática y en los manuales de ortografía destinados al público escolar. El trabajo se completa con un análisis previo del término/concepto ideología, palabra que ofrece gran interés por las vicisitudes semánticas por las que ha atravesado desde sus orígenes.
\end{abstract}

Palabras claves: historiografía lingüística; ideología; epistemología lingüística; glotopolítica; etnolexicografía; etnogramática; etnortografía

\begin{abstract}
The repercussion that ideology, as a filter that configures our view of the world, has in recent times in the linguistic discourse that is built on discourse itself (metadiscourse) is addressed here. After the proposal of Pérez Hernández (2000) of a new sub-discipline (ethnolexicography) that would include the study of dictionaries as texts that reflect an ideological vision of the world, we propose two parallel sub-disciplines: ethnogrammar and ethnorthography, which, also integrated in the framework of glotopolitics, would deal respectively with analyzing the way ideology is reflected in grammar texts and in spelling manuals intended for the school public. The work is completed with a previous analysis of the term/concept ideology, a word that offers great interest for the semantic vicissitudes that it has gone through since its origins.
\end{abstract}

Keywords: linguistic historiography; ideology; linguistic epistemology; glotopolitics; ethnolexicography; ethnogrammar; ethnorthography 


\section{Introducción}

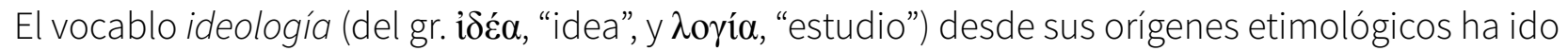
acumulando un amplio abanico de significados" ${ }^{1}$, aunque, siendo conscientes de la simplificación que supone, los reduciremos a los dos que aquí nos interesan: (i) conjunto de ideas fundamentales que caracteriza el pensamiento de una persona, colectividad o época, de un movimiento cultural, religioso o político, etc., y (ii) doctrina que a finales del siglo XVIII y principios del XIX tuvo por objeto el origen de las ideas (v. DLE, s.v. ideología). Entre ambas acepciones existe una clara filiación genética, pero también entre ellas se ha producido un llamativo proceso de inversión semántica pues "originalmente ideología significó el estudio científico de las ideas humanas; pero muy pronto el objeto pasó a dominar el enfoque, y el término pasó rápidamente a significar los propios sistemas de ideas" (Eagleton, 1997: 93). En efecto, la segunda acepción, la más literal, también la más remota, hace referencia a la doctrina filosófica que a finales del siglo xviii surgió en Francia, y cuyos afiliados, los ideólogos, centraron su atención en el "yo interior" del ser humano, en las ideas que configuran el pensamiento, convencidos de que el estudio científico de las mismas conduciría a una transformación de la sociedad. De este enfoque primordialmente cognitivo se pasó con el transcurso de los años a un enfoque sociocognitivo del concepto, donde el elemento "sociedad" irá adquiriendo una mayor presencia; una evolución que ha causado la inversión semántica del término ideología, más arriba apuntada.

A explicar este proceso dedicamos el epígrafe siguiente (2. La Ideología: de la Filosofía a la Lingüística, del individuo a la sociedad), al que se sumará un nuevo apartado (3. La ideología en el metadiscurso: su repercusión en la epistemología lingüística) donde expondremos las consecuencias que en la lingüística, y en concreto en los estudios sobre el discurso metalingüístico, ha tenido la introducción del concepto "ideología"; un concepto que, por su relevancia epistemológica, ha llegado a actuar como agente configurador de los diferentes campos de la disciplina.

\section{La Ideología: de la Filosofía a la Lingüística, del individuo a la sociedad}

\subsection{La Ideología como corriente filosófica y semiótica}

Será en el Institut National des Sciences et Arts donde Antoine Louis Claude Destutt, conde de Tracy, pronuncie por primera vez el término ideología, en el marco de las conferencias que sobre ciencias morales y políticas impartió entre 1796 y $1798^{2}$. El nuevo vocablo comenzó a difundirse en las discusiones de los ilustrados franceses con Napoleón Bonaparte, quien consideraba a los ideólogos unos

1. Puede consultarse la introducción a la historia de este concepto realizada por Eagleton (1997: 52-55).

2. El Institut National será el lugar de encuentro de los ideólogos; fue fundado en París en 1796 y sería suprimido en 1803 por Napoleón, por considerarlo un "foco de agitación ideológica". 
"metafísicos nebulosos" merecedores de menosprecio (Picavet, 1971: 29), llegando a atribuirles "todas las desgracias que han caído sobre nuestra querida Francia" (v. Eagleton, 1997: 98).

En efecto, los ideólogos franceses, por su indudable "vocación cívica y social" (García de la Madrid 2008: 95), trataron de transformar la sociedad que les tocó vivir, y de ahí su activa implicación en la revuelta situación política del momento. En el plano intelectual, estaban convencidos de que el abordaje conjunto de la ideología, la gramática y la lógica constituía la única "base sólida para el estudio de las ciencias morales y políticas" (García de la Madrid , 2008: 98); de modo que partieron del análisis de las ideas (cuyo origen exclusivo hacían residir en la sensación, de ahí el nombre de sensistas o sensualistas que también se les atribuye) para tratar de conseguir la renovación moral de la sociedad, sin necesidad de acudir a referentes metafísicos o teológicos, modelos que consideraban ya caducos.

Los ideólogos, como se ha dicho, pretendieron primordialmente describir la facultad de pensar (cognición) y para ello observaron el funcionamiento y desarrollo de las lenguas, concluyendo que en la sensación se encuentra el origen de las ideas, cuyo estudio se propone como sustituto de la tradicional metafísica aristotélica. De ahí les viene su interés por la ciencia del conocimiento, una metateoría ("science des sciences", Destutt, 1970: ix) que entendían integrada por tres disciplinas, las cuales ponían el foco en el mismo objeto -las ideas- si bien desde ángulos diferentes: la Ideología (su formación), la Gramática (su expresión) y la Lógica (su combinación) (Schlieben-Lange et al., 1989: I, 7). La teoría semiótica y lingüística sería, pues, desde un enfoque cognitivo, el núcleo de su proyecto de una ciencia unitaria.

El método de los ideólogos será preferentemente de tipo analítico, con dos etapas consecutivas y en una doble dirección, de ida y vuelta: en la primera, se descomponen las partes constitutivas del conjunto (análisis) para, en la segunda (síntesis), recomponerlas. Un método cuya aplicación a la gramática dio lugar a una extensa muestra de ejercicios escolares, cuya práctica ha llegado hasta nuestros días, originando de paso una lenta pero segura revolución en la descripción formal de las lenguas, especialmente en su nivel sintáctico (Calero Vaquera, 2008).

En definitiva, las bases de la Ideología como ciencia son (v. Zollna, 2004: 265): (i) una visión del mundo no dualista sino unitaria (i.e., las ideas dependen de los sentidos, no forman mundos aparte); (ii) el activo papel asignado al lenguaje en la formación de las ideas; (iii) el cultivo de la gramática general, como sistema lógico que manifiesta las estructuras cognitivas del pensamiento humano, y (iv) el interés por la educación y todas las disciplinas relacionadas (psicología, antropología, economía político-social, etc.).

La vigencia de las aspiraciones colectivas de los ideólogos en el contexto de la sociedad actual parece indiscutible. Aun así, hasta los años ochenta del siglo xx esta corriente filosófica ha tenido una "mauvaise étoile" (Moravia, 1986) a causa de: (i) la publicación del libro de F. Picavet Les idéologues (1971 [1891]), en el que estos no salían muy bien parados, y (ii) la marginación a la que los relegaron 
los historiadores de la Revolución francesa, más preocupados por detallar las consecuencias políticas y económicas de aquella que por relatar los logros culturales de la época.

\subsection{Las raíces filosóficas de la Ideología}

Tanto la ideología como la crítica ideológica arrancan de las dudas que, a partir de la época renacentista, comienzan a plantearse los intelectuales acerca de los fundamentos del orden social establecido, así como del concepto moderno de ciencia. En otro tiempo era impensable cuestionar el principio de unidad del mundo, avalado a partes iguales tanto por la filosofía como por la teología, de donde emanaban: (i) una serie de axiomas que regían para las ciencias de la naturaleza, y (ii) determinadas normas intocables que tutelaban el comportamiento social. Pero con la crisis de ese supuesto principio de unidad del mundo se abrieron vías para el surgimiento de la ideología y de la crítica a la ideología: vino a hacer aguas, así, no solo el sistema (social, político, religioso, etc.) entonces vigente, sino también la forzada identificación entre el método epistemológico de la metafísica y el de las ciencias naturales.

Fue a partir de los siglos xvi y xvii cuando se difundió por Europa el nuevo modo de pensamiento inductivo, de carácter empírico-experimental, que invalidaba el anterior, de tipo deductivo-especulativo. Este mismo método deductivo que combatirían los filósofos empiristas ingleses (David Hume, John Locke, etc.) se había visto reforzado por el racionalismo de René Descartes, quien en su Discours de la méthode (1637) postulaba, junto a la existencia de ideas innatas, la razón como principio del conocimiento, infravalorando en tal proceso el papel -poco fiable- de los sentidos. A este racionalismo epistemológico, John Locke, en su An essay concerning humane understanding (1690), replicará con su hipótesis de que el conocimiento procede de una doble fuente: (i) de las ideas que nacen de la reflexión y, además, (ii) de la experiencia que proporcionan los sentidos. También a Locke debemos el relevante papel que adquirirán los conceptos en su función mediadora entre la sensación y la palabra (v. Sánchez Blanco, 2007: 167).

El valor concedido a la observación y la experiencia fue capaz de revolucionar no solo los principios y métodos de la ciencia de la época sino también otros ámbitos más instrumentales como, por ejemplo, los métodos de enseñanza, que llegaron a desestimar las fórmulas apriorísticas como punto de partida en la didáctica de cualquier disciplina.

No debe olvidarse que la ideología contaba ya con un precedente en Francis Bacon, quien en su Novum organum (1984 [1620]) había expuesto los principios de su método científico, experimental e inductivo, basado en la observación de la naturaleza. Un método que vendría a sustituir al que Bacon consideraba poco riguroso organon aristotélico, asentado no en la observación directa de los hechos sino en el propio intelecto humano; lo que, en opinión del filósofo inglés, no salvaguardaba de modo suficiente contra el dogmatismo y los errores, es decir, contra los que él denominaba ídolos (v. Bacon, 1984: 41). 
En sus orígenes, la crítica de Bacon a la diversidad de errores humanos permanece en el plano meramente filosófico, a diferencia de la que se impondrá más tarde en la ilustración francesa: es decir, Bacon no pretendía trasladar su método empírico, que aplicaba solo a las ciencias de la naturaleza, a otros terrenos, como la teología o la política; será con la aplicación posterior de la doctrina de los ídolos a una crítica general de los prejuicios (préjugés) cuando la ideología, como construcción teórica, incida de lleno en el ámbito político-social.

Aun siendo dos tendencias muy distintas en sus planteamientos y métodos, como se acaba de ver, racionalismo y empirismo compartían una serie de rasgos que vinieron a promover y entronizar la ideología como ciencia en los últimos años del siglo XIX. Por tanto, hay que conceder que "la génesis

de la ideología hubiera sido inconcebible sin la asimilación y maduración de dos corrientes del siglo xvi enfrentadas con más empeño que razones: el racionalismo y el empirismo" (García de la Madrid, 2008: 105).

\subsection{El papel central del lenguaje en el marco teórico de la Ideología}

Para los ideólogos el lenguaje desempeña un papel crucial en el proceso cognoscitivo. Para uno de sus filósofos precedentes, É. Bonnot de Condillac, el lenguaje es mucho más que un simple medio de comunicación: es una facultad que posibilita la propia reflexión y el resto de las operaciones mentales, un instrumento imprescindible para descomponer nuestras ideas y poder observarlas sucesivamente una por una:

Les langues ne se perfectionnent qu'autant qu'elles analysent; au lieu d'offrir à la fois des masses confuses, elles présentent les idées sucessivement, elles les distribuent avec ordre, elles en font différentes classes; elles manient, pour ainsi dire, les élémens de la pensée, \& elles les combinent d'une infinité de manières [...]. (Condillac, 1789: 134)

En otras palabras: si el ser humano es capaz de pensar, ello es posible gracias al lenguaje, dado que ambas facultades cognitivas se van desarrollando en un proceso paralelo e interdependiente. Por tanto, para entender el origen de las ideas, así como la manera en que se expresan y combinan, es preciso analizar el lenguaje (grammaire):

Je regarde la grammaire comme la première partie de l'art de penser. Pour découvrir les principes du langage, il faut donc observer comment nous pensons: il faut chercher ces principes dans l'analyse même de la pensée. (Condillac, 1789: 106)

Esta visión supone una novedad respecto a la concepción que Locke mantenía de la relación lenguaje/pensamiento pues "mientras en Locke lenguaje y pensamiento eran entidades diferentes, en Condillac el lenguaje no es sólo un instrumento del pensamiento, sino su razón misma” (García de la Madrid, 2008: 113). La gramática, pues, como expresión de las ideas, junto a la lógica, que ejerce de guía en la combinación de las ideas. En esa tríada interactiva (ideología, gramática, lógica), lenguaje 
y pensamiento mantienen una especial interdependencia, en opinión de Condillac y sus seguidores, los ideólogos; y las diferentes lenguas particulares (langues) serán consideradas concreciones de una capacidad cognitiva común a la especie humana: el lenguaje (langage). A esas lenguas particulares se les atribuye, por otra parte, cierto influjo selectivo en la propia cognición: "Nous pensons dans notre langue et d'après notre langue" (Condillac, citado por Hassler, 1990: 139). Nuestra lengua influye, por tanto, en nuestra manera de pensar, lo que con el tiempo servirá para amparar la defensa de una conciencia de identidad nacional, sustentada sobre los cimientos de una identidad lingüística. Al respecto, el célebre capítulo XV "Du génie des langues" del Essai de Condillac deja claro que "le caractére [sic] des Peuples influe sur celui des Langues" (Condillac, 1746: 197). De hecho, la propagación de estas ideas filosóficas coincide en nuestro país con las recomendaciones ${ }^{3}$ acerca de la conveniencia de que la lengua castellana sea utilizada como instrumento de comunicación al menos en la primera y segunda enseñanza, dado que la lengua materna -se argumenta- es el vehículo más adecuado para la transmisión de las ideas.

A pesar de la ilusión de homogeneidad, los ideólogos franceses nunca formaron un grupo sin cisuras en sus planteamientos y soluciones. Ricken (1986: 19-43), por ejemplo, ha explicado las divergencias existentes entre Condillac y algunos de los ideólogos que le sucedieron: si para Condillac, Destutt y sus seguidores más fieles las aptitudes intelectuales no eran más que sensación transformada, para otros (Degérando, Prévost, Laromiguière, etc.) el papel de los signos en la generación de las ideas será mínimo, por lo que lanzarán nuevas hipótesis ya en un nuevo marco de sensualismo moderado. En esta nueva etapa de la ideología se rehuirá de los extremos idealismo-racionalismo / materialismo-empirismo, con lo que se inaugura una nueva tendencia que pretendía revalorizar un tipo de actividad mental autónoma, y cuyo principal representante será Maine de Biran (v. Eschbach, 1986: 59-72).

\subsection{La transformación conceptual de la ideología: del individuo a la sociedad}

Como se dijo más arriba, es obligado reconocer la amplia repercusión social que alcanzaron las propuestas de los ideólogos, especialmente en el terreno pedagógico pues, como cualquier ideología, también la suya estaba "orientada hacia la acción" (Eagleton, 1997: 74). Aun así, el enfoque que habían dado a la disciplina Ideología ("ciencia de las ideas") se mantenía fiel a la etimología del término, que apuntaba a las altas esferas de la teoría del conocimiento, donde la cognición del individuo seguía siendo el principal objeto de estudio, ya que se trataba de desvelar sus estructuras conceptuales. En consecuencia, el ingrediente social, como elemento epistemológico, no hallaba todavía acomodo en el sólido edificio teórico levantado por los ideólogos, que seguían fascinados por desvelar la relación entre pensamiento y lenguaje. A partir de aquí, sin embargo, asistiremos a la paulatina conversión de esa pura especulación filosófica -aunque, insistimos, llevando anexas ya preocupaciones sociales- en una teoría sociológica, con diferentes versiones, en la que se conside-

3. Publicadas en el "Informe de la Junta creada por la Regencia para proponer los medios de proceder al arreglo de los diversos ramos de Instrucción pública”, Cádiz, 9 de septiembre de 1813. 
rará ya la función social de las opiniones y representaciones mentales, y donde la "interacción social" aparecerá integrada por derecho propio en el sistema disciplinar.

Justamente será en la misma Francia, y casi de forma simultánea a los ideólogos, donde el centro de interés sufrirá un giro radical: del individuo, como ser pensante, la atención se desplazará al grupo, como ente social, gracias en buena parte a las doctrinas de filósofos como Henri de Saint-Simon, uno de los teóricos fundadores del socialismo francés y muy relacionado con Augusto Comte; ; o Charles Fourier, uno de los padres del cooperativismo, o Pierre-Joseph Proudhon, teórico del pensamiento anarquista. Todos ellos reflexionaron sobre las necesidades de la vida social, contribuyendo así a formalizar el espectacular vuelco protagonizado por la Filosofía a lo largo del siglo xix, en ese movimiento centrífugo que va del interior del individuo a la sociedad de la que forma parte.

A esta nueva visión de los teóricos de la Filosofía no era ajeno el curso de los acontecimientos políticos y sociales del momento histórico. En efecto, "la época que va de 1815 a 1848 [...] es sin duda la más abundante en revoluciones o intentos de tales en toda la historia de Europa" (Comellas García-Llera, 1991: 7). Solo teniendo en cuenta que "la revolución es un artículo en alto grado exportable" (Comellas García-Llera, 1991: 18) pueden explicarse las agitaciones sociales ocurridas en 1848 y conocidas genéricamente como "la primavera de los pueblos" (Hobsbawm, 2007: cap. II). Tales revueltas triunfaron en el centro del continente europeo, en un intento de cambiar la situación política en aquellos países gobernados por monarcas o príncipes absolutos, bajo la demanda de alcanzar la anhelada "república democrática y social". Si bien es cierto que hubo un rápido debilitamiento de estas revueltas, los revolucionarios lograron un gran cambio que será ya irreversible: "la abolición de la servidumbre en el imperio de los Habsburgo", junto a otras ganancias sociales (v. Hobsbawm, 2007: cap. II).

Para entonces (mediados del siglo xix) la palabra ideólogos había llegado a adquirir un sentido peyorativo, equivalente a "doctrinarios", significado que, como vimos, se remonta a Napoleón, pero que ha mantenido su vigencia hasta épocas más actuales 5 . En esta nueva acepción preñada de connotaciones despectivas la ideología se concebirá ya como un equivalente del "discurso dogmático", un discurso utilizado para desprestigiar a determinado sistema de pensamiento o a cierta concepción del mundo; un discurso proselitista y, en última instancia, de adoctrinamiento interesado.

Karl Marx retomará esta noción despreciativa del término en su obra La ideología alemana (1846), escrita en coautoría con Friedrich Engels, donde hallamos una crítica explícita a los ideólogos, cuyas "abstracciones, de por sí, separadas de la historia real, carecen de todo valor" (citado por Rodríguez Paniagua, 1972: 72). Para Marx, como para Engels, la ideología se acerca al significado de "falsa conciencia" (frente a "ciencia"), lo que le servirá para catalogar a los sistemas filosóficos, jurídicos,

4. Creador del positivismo, así como del término sociología (1839), disciplina que desarrollará Émile Durkheim en Les Règles de la méthode sociologique (1895).

5. "En un discurso del 21 de agosto de 1923, Hitler culpaba por la revolución de noviembre de 1918 a ideólogos, criminales y bandidos" (Lenk, 2001: 32.). 
políticos y religiosos como fantasías, "ilusiones sobre la realidad". En su opinión, las ideologías no solo son sistemas erróneos que distorsionan el mundo real, sino que se presentan también como sistemas de justificación de esa misma realidad que desvirtúan. Por todo ello se ha dicho que "no es casual que pueda interpretarse toda la obra de Marx como una crítica de las ideologías" (Lamo de Espinosa et al., 1994: 191). Sobra decir, por otra parte, el papel central que la sociedad desempeña en el pensamiento de Marx, hasta tal punto que es en las relaciones sociales, y no en el propio individuo, donde el autor de El capital (1867, vol. I) asienta la esencia del ser humano; una sociabilidad que, en su opinión, se realiza en la praxis del trabajo, haciéndole así merecedor del título homo laborans entre los seres de la naturaleza (v. Lamo de Espinosa et al., 1994: 181).

El concepto negativo de la ideología sobrevivirá en los teóricos marxistas herederos de Marx: Georg Lukács, Lucien Goldmann, Antonio Gramsci... Entre ellos, y ya en pleno siglo xx, Louis Althusser sugiere que la ideología representa "la manera en que yo 'vivo' mis relaciones con el conjunto de la sociedad", una cuestión de "relaciones vividas", pasando así de una teoría cognitiva a una teoría afectiva de la ideología (v. Eagleton, 1997: 40-43).

El papel cada vez más relevante del concepto "sociedad" en las teorías del conocimiento encontrará un nuevo hito otra vez en Francia, país que a finales del siglo xix será la cuna del nacimiento de la Sociología como "ciencia de las instituciones", fundada con el objetivo de identificar los "hechos sociales" de carácter estructural. A Émile Durkheim se atribuye el establecimiento de los principios de esta nueva ciencia, que sigue el programa bosquejado por Comte, donde el lado social del ser humano se presenta como "la más alta realidad". Durkheim concibe la sociedad no solo como un producto diferente a la suma de las individualidades sino también como ente activo, coercitivo incluso, que llega a conformar tanto el pensamiento y sus categorías como las normas morales del propio individuo, en un claro anticipo de la hipótesis etnolingüística de Sapir-Whorf.

En la segunda mitad del siglo xix las nociones y métodos de la Sociología comienzan a llegar a oídos de los teóricos del lenguaje, quienes van tomando gradual conciencia de que el análisis de los fenómenos lingüísticos es indesligable de la propia sociedad humana. Si, en este aspecto, en Norteamérica hay que recordar a William D. Whitney, en Europa el Cours de linguistique générale (1916) de Ferdinand de Saussure contribuyó a generalizar la idea de que el lenguaje es una institución fundada en la naturaleza social del ser humano. Será Antoine Meillet quien haga girar buena parte de sus escritos en torno al sesgo social del hecho lingüístico, como principal representante de la escuela sociológica francesa, a la que también pertenecieron J. Vendryès (Le langage, 1921), Albert Dauzat ("L'orientation sociologique actuelle dans les sciences du langage", 1920) y Marcel Cohen (Pour une sociologie du langage, 1956). Esta última obra se publica casi al tiempo de la fundación de la Sociolingüística, disciplina que se ocupará de la lengua como sistema de signos en un contexto social y como reflejo de unas estructuras sociales determinadas. Una nueva vía de estudio en la relación lenguaje/sociedad es la que considera a esa facultad humana como hecho social, como un tipo de comportamiento o modo de acción (antropología lingüística), línea en la que destacó el etnólogo Bronislav Malinowski. 
En la actualidad, y para cerrar el repaso a la evolución del concepto "ideología", se tiende a usar el término correspondiente en sentido neutro, despojado de connotaciones peyorativas, para aludir al conjunto de ideas que forman parte de un sistema de creencias, representaciones, sentimientos, valores sociales e instituciones, mediante el que las personas, de forma colectiva, interpretan y organizan la realidad, dando así sentido y coherencia al mundo en que viven. Tal sistema de creencias se convierte así en un rasgo claramente identitario, que identifica a los sujetos de la misma manera que su pertenencia a una clase social, un partido político, una religión, un país, etc. En esta línea nos interesan especialmente aquellos autores que han atendido al juego desempeñado por el poder social en el propio lenguaje, como Valentin N. Voloshinov (El marxismo y la filosofía del lenguaje, 1929), considerado el fundador del Análisis del discurso (AD), o Michel Pêcheux, quien defiende en Lenguaje, semántica e ideología (1975) que todo discurso se encuentra necesariamente inserto en relaciones ideológicas. A las escuelas inscritas en esta corriente (con distintas variantes encabezadas por W. Labov, M.A.K. Halliday, R. Fowler, etc.) les une el propósito de rastrear las huellas del poder social en las estructuras léxicas y sintácticas de las lenguas (Eagleton, 1997: 246-247). Entre esas escuelas es destacable, por sus repercusiones en el ámbito hispánico, la liderada por Teun A. van Dijk:

[...] si queremos saber qué apariencia tienen las ideologías, cómo funcionan y cómo se crean, cambian y reproducen, necesitamos observar detalladamente sus manifestaciones discursivas (van Dijk, 1999: 19, cursiva en el original).

Tras definir la(s) ideología(s) con una neutra acepción ("la base de las representaciones sociales compartidas por los miembros de un grupo", van Dijk, 1999: 21; cursiva en el original) y entendiéndola(s) en un sentido amplio ${ }^{6}$, el autor holandés hace descansar el marco general de su teoría en el triángulo conceptual "cognición", "sociedad" y "discurso", de donde resulta un nuevo acercamiento multidisciplinario a la ideología, dado que el "análisis del discurso está relacionado de una manera múltiple con una descripción cognitiva y social” (van Dijk, 1999: 19). Un abordaje multidisciplinar que, es cierto, estaba ya presente en la tríada epistemológica de los ideólogos franceses (ideología, gramática y lógica) pero que ahora se amplía con el añadido del ingrediente "sociedad" (v. fig. 1). Este elemento se integra con el pensamiento y su expresión en una triple y sólida alianza, lo que ha permitido saltar del enfoque puramente cognitivo del lenguaje al sociocognitivo.

6. Van Dijk reconoce que existen ideologías "no dominantes", esto es, de oposición o resistencia al poder establecido; pero también estas son incluidas en su análisis. 


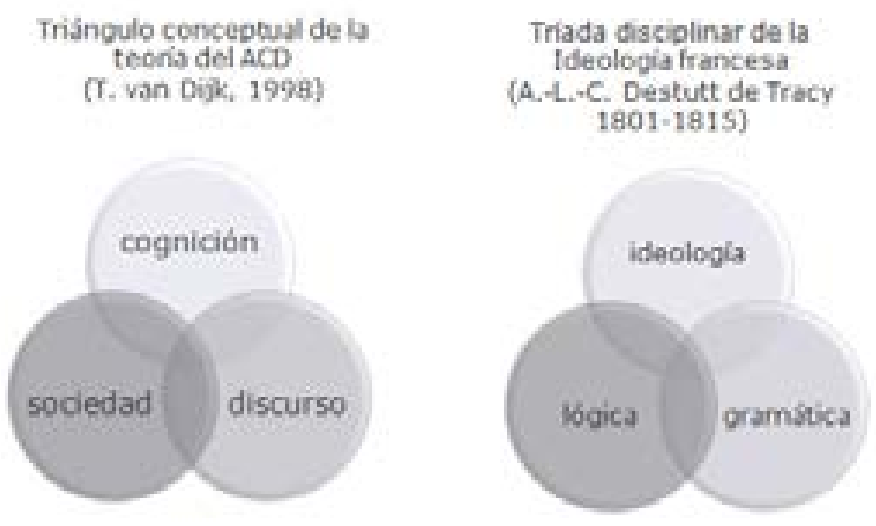

Fig. 1: Marco general de las teorías de van Dijk y de Destutt de Tracy [Elaboración propia]

Se observará, por último, que, por encima de la neutralidad del diseño científico, la corriente promovida por van Dijk (Análisis crítico del discurso, o ACD) aspira a evaluar y enjuiciar los hechos discursivos que se describen, sin obviar la denuncia de las relaciones de dominación, poder y desigualdad social en aquellas situaciones comunicativas donde se produzcan.

\section{La ideología en el metadiscurso: su repercusión en la epistemo- logía lingüística}

En las líneas siguientes veremos cómo la ideología, entendida aquí en su primera acepción del DLE, i.e., como un "conjunto de ideas fundamentales que caracteriza el pensamiento de una persona, colectividad o época, de un movimiento cultural, religioso o político, etc.", ha influido en la categorización y reorganización de las (sub)disciplinas del ámbito de la lingüística, gracias a la relevancia formal que se le concede al elemento "ideología" cuando hace su presencia en el metadiscurso, es decir, en el discurso que se construye acerca del propio discurso lingüístico (textos lexicográficos, gramaticales, ortográficos...). 


\subsection{Ideología y diccionario}

No es ninguna novedad el estudio de las marcas ideológicas en obras de carácter lexicográfico; de hecho, mucha tinta se ha vertido ya en la bibliografía especializada española (Ahumada, 2006: 41-42) y extranjera intentando dilucidar si es conveniente, o reprobable (y, en ese caso, si es evitable) la aparición de huellas ideológicas en las obras lexicográficas. Contamos, pues, en la historia metalexicográfica, por una parte, con especialistas que han abogado por una neutralidad impoluta del redactor del diccionario (Seco, 1987; Casares,1992), situados frente a quienes justifican la aparición de improntas ideológicas en este tipo de obras (Dubois y Dubois, 1971; Blecua Perdices, 1990; Pascual y Olaguíbel, 1992; Forgas Berdet, 1996, 2001), consideradas más bien una creación ideológica, la instantánea de un momento cultural, dado que reflejan, tanto en la elección de las entradas, como en las definiciones y en los ejemplos, la sociedad y la mentalidad dominantes. Sus encontradas opiniones han dado lugar a un debate metalexicográfico de primer orden, como muestran las siguientes citas:

Si a las palabras [en el discurso] les está permitido ser cariñosas, encomiásticas, despectivas o irónicas, al lexicógrafo no le es lícito imitarlas. En su vida privada, en sus ratos de ocio, el redactor de un diccionario puede escribir páginas coloristas, inventar arriesgadas metáforas, componer versos gongorinos o sentar plaza de humorista; [...] pero todo esto deberá dejarlo en el guardarropa antes de entrar en la oficina lexicográfica. (Casares, 1992: 142)

D'une manière ou d'une autre, les exemples qui ont à la fois une fonction linguistique et une signification culturelle engage l'éthique et l'esthétique des lexicographes. Ils forment un ensemble d'assertions sur le monde, qui implique une idéologie, celle d'une communauté à laquelle le lexicographe s'identifie, mais aussi une manière personnelle de juger des phrases et des messages qui s'y trouvent. (Dubois y Dubois, 1971: 54)

El perfil ideológico del autor o autores (de un diccionario) y el del grupo social al que pertenecen influye en la tarea lexicográfica desde el momento mismo de la concepción de la obra, puesto que cada una de las decisiones que conlleva su factura es una decisión marcada ideológicamente. (Forgas Berdet, 2001: s.p.)

Es cierto que ha habido otros momentos de la historia de la lexicografía en los que era aún más evidente la intromisión de una determinada ideología en los textos. Así, contamos con estudios demostrativos de que la expresión de credos políticos, orientaciones filosóficas o dogmas religiosos se inmiscuyó descaradamente tanto en la macroestructura (presentación, prólogo, observaciones preliminares, etc.) como en la microestructura (cuerpo de la definición, textualizaciones y ejemplos) de los primeros testimonios lexicográficos. Rodríguez Barcia (2008), por ejemplo, ha analizado el caso de las sucesivas ediciones del diccionario de la Real Academia Española, que con razón considera 
[...] especialmente interesante, pues desde siempre su trabajo estuvo vinculado a los grupos que ostentaban el poder político, religioso y social, con lo que la cosmovisión de los redactores coincidía en parte con la ideología de la que participa la 'elite', por lo que el estudio de la producción lexicográfica de esta institución puede revelar aspectos de gran interés para el dibujo de la sociedad española. (Rodríguez Barcia, 2008: 13)

Es, pues, innegable que la producción lexicográfica actual ha conseguido atemperar las huellas ideológicas presentes en toda producción humana. Pero, como explica Medina Guerra (2003), tanto los criterios editoriales como las personas que redactan el diccionario, así como el público al que este va dirigido, siguen siendo en la actualidad factores determinantes de la ideología que subyace en las páginas de cualquier diccionario. Recuérdense, si no, las polémicas que todavía suscita el sesgo ideológico de la Academia en su tratamiento y representación de las mujeres en el diccionario (v. Lledó et al., 2004). En efecto, como cualquier producto cultural, el diccionario nace per se con una marca ideológica, sutil a veces, pero siempre ineluctable. Es lo que ha llevado a algunos especialistas (sobre todo de Hispanoamérica, p. ej. Pérez Hernández, 2000) a utilizar, para designar este tipo de estudios, el término de Etnolexicografía, o Socio-etnolexicografía,

[...] acercamiento que pretende respaldar la idea de que los diccionarios, más que puros instrumentos de descripción aséptica y objetiva de las lenguas, son textos que ofrecen una particular e ideológica visión del mundo y de la historia, cultura y sociedad de los hombres (Pérez Hernández, 2000: 59).

\subsection{Ideología y gramática}

Como producto cultural que son, también los libros de gramática son susceptibles de presentar en sus páginas marcas ideológicas, orientaciones de pautas de conducta, indicaciones morales, etc. Al igual que sucede con el lexicógrafo, el autor de un tratado gramatical es hijo de su tiempo, de su cultura y de su sociedad y se encuentra, por tanto, sometido a unos modelos y estereotipos socioculturales que en ocasiones (de forma consciente o inconsciente) emergen y quedan plasmados en su producción científica. Ya en 1984 Montserrat Martinell advertía sobre la intención didáctico-moralizadora que albergaban muchos de los ejemplos contenidos en la Gramática académica de 1796:

La virtud, la justicia, el estudio y la milicia son en este caso temas privilegiados, sin que falten las alusiones o la presencia de otros temas como la familia, las riquezas o la vida humana [...]. Juicios de valor, generalizaciones, sentencias, presentación de hechos concretos, así como recursos retóricos, todo vale para transmitir unos valores, una tradición, y para inculcar unas actitudes (Martinell, 1984: 168-169)

Es esta una práctica generalizada entre los autores de la tradición hispánica, como demuestra la siguiente cita (una de las muchas posibles que podríamos aducir aquí): 
Se han escogido cuidadosamente ejemplos de buen gusto, [...] para comprobar las observaciones del texto, teniendo además la ventaja de envolver los más de ellos un pensamiento o máxima moral, que al propio tiempo que sirve para ilustrar la razón de los niños, pueda insensiblemente ir formando también su corazón. (De Miguel, 1882: xi)

La misma costumbre es apreciable en las gramáticas de la tradición editadas en Hispanoamérica, hecho que va en paralelo con la magnitud de los acontecimientos sociopolíticos que tuvieron lugar en esa región en el transcurso del siglo XIX. Así lo demuestra Narvaja (2008: 285), quien se ha dedicado a "indagar las características y función de los ejemplos en el modelo de gramática escolar [en el Chile de 1842 a 1862] destinado a la consolidación del Estado nacional y a la ampliación del sistema educativo". Para ello se centra en el análisis de los manuales de gramática que Andrés Bello publicó con vistas a la enseñanza escolar chilena, cuyos textos se nos muestran notablemente "sacralizados", marcados por las recomendaciones y advertencias morales y, cómo no, repletos de consignas de amor a la propia patria chilena, recién independizada de la metrópoli. Bello, entre otros representantes del movimiento ilustrado hispanoamericano, se propuso, a la vez que difundir el conocimiento entre el mayor número posible de sectores sociales, la tarea de "disciplinar sujetos y prácticas" (Narvaja, 2008: 308). De modo que algunas de las funciones en esa disciplina y "sujetamiento" de los individuos, propias de las "instituciones que tienen el monopolio del discurso moral" (i.e., la Iglesia y la familia), terminarán siendo "asumidas por el aparato escolar" (Narvaja, 2008: 287). Las conclusiones del trabajo de Elvira Narvaja, aunque, como se ha dicho, centrado en las gramáticas escolares de Bello, permiten ser extrapoladas a otros muchos ejemplos de autores de gramáticas didácticas.

Es el caso de Cosme Pérez Cuadrado, autor de un Curso superior de Gramática española simbólica e intuitiva (1946), donde claramente se plasma la ideología de la época gracias al método "simbólico" que utiliza, definido como:

[la] representación por semejanza y correspondencia de cada una de las partes de la oración en los miembros y dependencias de una familia, representando las oraciones en diversos actos y relaciones de la vida humana, y, por último, simplificando el conocimiento de las oraciones compuestas, por medio de conjunciones claves. (Pérez Cuadrado, 1946: 8)

El autor afirma que, tras comprobar las dificultades de sus alumnos a la hora de categorizar las palabras, se le ocurrió "personificar" las categorías gramaticales, estableciendo una ingeniosa asociación entre las funciones que -en el plano lingüístico- desempeñan los vocablos y las que pueden ejercer -en el ámbito social- los miembros de una familia:

7. Los titulados Gramática Castellana para el uso de las escuelas (1851) y Compendio de Gramática Castellana escrito para el uso de las escuelas primarias (1861). 
Siendo la familia la asociación natural y lógica de cuantos tienen una razón de consanguinidad o convivencia, y siendo el conjunto armonioso del lenguaje una verdadera asociación lógica y natural también de palabras, alguna semejanza (y a mi juicio coincidencia) existirá entre las funciones que desempeñan las nueve partes de la oración, y las que puedan desempeñar los elementos de una familia bien organizada, bajo el elemento primordial que es el sustantivo o cabeza de familia. (Pérez Cuadrado, 1946: 22)

Y a partir de esta idea intentará definir cada una de las nueve categorías gramaticales que él, sin apartarse de la doctrina académica contemporánea, distingue:

- $\quad$ el sustantivo, "que es independiente en la oración [...], lo es en la misma forma que el cabeza de familia que de nadie depende" (p. 22);

- $\quad$ el adjetivo, "que no va solo, sino calificando o determinando al substantivo, lo hace en la misma forma que la esposa que no debe ir sola, sino unida a su esposo (el sustantivo)" (p. 23);

- $\quad$ el pronombre, "que representa al nombre para evitar su repetición o constante presencia, lo hace del mismo modo que el administrador de la casa, que evita la constante presencia de su dueño (el sustantivo)" (p. 23);

- $\quad$ el artículo, "que pertenece exclusivamente al sustantivo o palabra que haga sus veces, tiene gran semejanza con el bastón, objeto que solamente suele llevar el caballero" (p. 23);

- El verbo, "que muchas veces es cópula y denota principalmente acción (movimiento), representado en el hijo, lazo que afianza el matrimonio y en el que todo es movimiento y vitalidad" (p. 23);

- El adverbio, "que se junta al verbo, al adjetivo y a veces a otro adverbio, tiene gran semejanza con la función que desempeña un criadillo que, encargado del hijo, se halla en íntima relación con la madre (adjetivo) [...]" (p. 23);

- El prefijo o preposición, "que [...] realiza función semejante a la del abuelo paterno, aconsejando la buena armonía y dependencia que debe existir principalmente entre el cabeza de familia, su señora y el nieto (verbo)" (p. 23);

- La conjunción, "que sirve para enlazar palabras u oraciones, realiza semejante función a la de una chica encargada de llevar y traer recados, siendo enlace entre los elementos de la familia y sus amistades" (p. 23-24);

- La interjección, "que goza de independencia, siendo el medio de expresión de las emociones y sentimientos, realiza análoga función a la de la portera de esta casa que vive de impresiones y emociones constantes, se expresa durante gran parte del día con interjecciones, y es independiente de esta familia simbólica" (p. 24). 
Este "procedimiento simbólico" (metafórico, en definitiva), como fórmula comparativa entre dos entidades situadas en diferentes niveles de abstracción, responde a uno de los más conocidos procesos cognitivos de aprendizaje y percepción. Como han demostrado Lakoff y Johnson ${ }^{8}$ (1986), el ser humano tiende a traducir sus experiencias más abstractas, lejanas o difusas en términos más concretos, familiares o perfilados:

Conceptualizamos característicamente lo que no es físico en términos de lo físico, es decir, conceptualizamos lo menos claramente delineado en términos de lo claramente delineado. (Lakoff y Johnson, 1986: 99)

Pero al margen de esa tendencia humana de intentar traducir los fenómenos abstractos en experiencias concretas, este procedimiento nos interesa ahora por la posibilidad que ofrece de suministrar e insertar datos del ámbito cultural, ideológico, etc. de una época determinada en obras gramaticales de la tradición. En el Curso de Pérez Cuadrado, por ejemplo, podemos apreciar una noción de familia ciertamente algo trasnochada ya para la mentalidad actual; así,

a) la trascendencia que se otorga a la paternidad, frente a la maternidad, rotundamente ignorada: "Tú [el verbo] eres hijo de don Sustantivo, recibiste de Dios y de tu padre la esencia y la existencia..." (p. 65);

b) el concepto monolítico de la familia tradicional -padre + madre + hijo(s)- como única fórmula posible: "Mira, Sustantivo, cuando nos reunimos los tres en íntima asociación, todo el mundo dice: Ahí va la verdadera familia..., donde los tres somos necesarios" (p. 192-193);

c) la importancia que se concede a la función del "cabeza de familia", ejercida por el varón: "Mira, hijo, igual que yo soy el cabeza de familia, independiente, y bajo mi tutela vives tú y los demás miembros de esta casa..." (p. 25);

d) la dependencia absoluta que mantiene la esposa (el adjetivo) respecto del marido, ya que "no puede ni debe ir sola a ninguna parte" (p. 36), siendo ése su "verdadero papel" (ser adjetivo, nunca sustantivo): "Ya sé que desde que te has casado con D. Sustantivo, no eres independiente, en tu vida ni en tus relaciones" (p. 35), etc.

Otros muchos diálogos, que en aquellos tiempos se recibirían con naturalidad absoluta por parte del auditorio escolar, hoy sería impensable encontrarlos reproducidos en el contexto de un aula por su evidente tufo racista:

El Señor.- Ese cutis no blanqueará, por más que se lave.

El Negro.- Usted qué sabe si, a fuerza de lavarme, lo consiguiese. (Pérez Cuadrado, 1946: 281)

En definitiva, el recurso didáctico del "simbolismo", por el que se establecen correlatos entre los planos lingüístico y sociocultural, permite rastrear elementos del ámbito cultural, ideológico, etc. de una época determinada en obras gramaticales de la tradición.

8. Puede verse también Swiggers y Lioce (2003) para otros ejemplos de antropomorfización de categorías gramaticales. 
A tenor de estas reflexiones, reivindicamos en su momento (v. Calero Vaquera, 2004) un nuevo espacio disciplinar que comprendería el estudio de cómo las costumbres, el saber, las experiencias, los comportamientos, etc. de una determinada sociedad quedan plasmados en las correspondientes obras gramaticales (o lexicográficas, etc.) del momento; un nuevo espacio situado en la intersección de dos ramas del saber: la Lingüística y la Antropología. Es cierto que ya desde principios del siglo XX existe una disciplina híbrida que se ocupa de investigar las relaciones existentes entre el lenguaje y la cultura, habiendo recibido distintas denominaciones: etnolingüistica, lingüística antropológica, lingüística cultural, etc.9; pero entendemos que ninguno de estos campos recubre de forma cabal el objeto de estudio de lo que provisionalmente hemos denominado etnogramática (entendido aquí el elemento compositivo gramática en su acepción de "libro donde se analizan los elementos de una lengua y sus combinaciones") y que en su momento definimos como:

Disciplina de carácter metalingüístico que se ocupa de analizar el modo como la ideología, las costumbres, las creencias, las experiencias, los comportamientos, etc. de una determinada sociedad quedan reflejados, con una finalidad didáctica y de transmisión de valores, en los textos gramaticales, especialmente en aquellas secciones complementarias a los contenidos puramente teóricos como puedan ser los ejemplos, ejercicios, ilustraciones, etc. (Calero Vaquera, 2004: 324)

La etnogramática (al igual que la ya vista etnolexicografía o socio-etnolexicografía) se situaría, pues, en un nivel de discurso de tipo metalingüístico ("lenguaje que se usa para hablar del lenguaje"), es decir, en un plano diferente a aquel en que se ubican las materias señaladas más arriba, que se ocupan, sin mediaciones, de "la lengua y el mundo"10.

\footnotetext{
9. Sin que hayan faltado los intentos de realizar nuevas subdivisiones en ese marco genérico disciplinar, dependiendo de que el punto de partida sea el lenguaje o la cultura (lingüística etnográfica/etnografía lingüística; v. Coseriu, 1981), o según los escenarios e intereses que dominan en un momento concreto (lingüística boasiana/etnosemántica/etnografía del habla; v. Palmer, 2000).

10. Como señalan Dubois y Dubois (1971: 49), "un dictionnaire est un ouvrage de seconde main: son objet, ses données observables ne sont pas la langue et le monde, mais ce que l'on dit de la langue et du monde", observación que también podría aplicarse a la (etno)gramática como disciplina.
} 


\subsection{Ideología y ortografía}

También los manuales de ortografía, al igual que los diccionarios, las gramáticas y otros textos usados en las escuelas (p. ej., los libros para la enseñanza de la lectura), pueden informarnos acerca de la concepción del mundo, ideales, aspiraciones, etc. que los educadores de épocas pasadas transmitían a los estudiantes para que los interiorizaran y los mantuvieran vigentes a lo largo de su vida.

Muestra de ello es la obra titulada Plan concéntrico de ortografía. Curso elemental, de Nicasio H. García (1947), inscrito en el sistema de reforma de la enseñanza primaria en Uruguay conocido como "Reforma Valeriana" (1876-1879). En concreto, el libro se enmarca en el denominado "plan concéntrico" educativo que, inspirado en los métodos pedagógicos que por entonces tenían vigencia en Alemania, Francia e Inglaterra, comenzó a aplicarse en algunos países del Cono Sur americano (como Chile o Uruguay) en los años ochenta del siglo XIX. Este "plan concéntrico" vino a sustituir a la caduca enseñanza de materias aisladas e independientes unas de otras por la instrucción simultánea en varias secciones.

El citado libro nos interesa aquí por constituir un nuevo ejemplo de manual escolar donde ha quedado impresa una determinada huella ideológica, en la línea de lo visto en los párrafos precedentes. Si más arriba mostrábamos que esas huellas abundan en las obras de carácter lexicográfico o gramatical, ahora se comprueba que en los textos de tema ortográfico también sus autores se pueden ver tentados a introducir información cargada de ideología con la finalidad de dirigir interesadamente el pensamiento y la conducta de sus pequeños lectores. Pero, ¿de qué manera y con qué instrumentos discursivos? Veámoslo.

No se trata aquí, en este manual uruguayo, de proponer una reforma ortográfica más, con la idea de simplificar la ortografía del español, al estilo de las propuestas por Domingo Faustino Sarmiento o Andrés Bello en el Chile de la primera mitad del siglo XIX11. El tiempo de las aventuras reformadoras de la ortografía, con plausibles fines democráticos y, de paso, de consolidación de la propia identidad, había pasado ya para los intelectuales y gobernantes de los países hispanoamericanos de mediados del siglo XX ${ }^{12}$. Serán, pues, otros los mecanismos discursivos de los que Nicasio H. García se servirá en este Plan concéntrico de ortografía para adoctrinar a sus jóvenes discípulos en la construcción de una identidad nacional y en su comportamiento como futuros ciudadanos en el seno de esa entidad política. Los siguientes:

11. Propuestas que se inscriben "en un emprendimiento más amplio que es el desarrollo de una cultura hispanoamericana moderna para lo cual la marcación en la lengua escrita es la señal de cambio" (Narvaja, 2008: 185).

12. En efecto, el año de 1927 había significado el comienzo de la aceptación unánime, en todo el orbe hispanohablante, de la norma ortográfica impuesta por la Real Academia Española. 
a) los ejemplos en los que se hacen recomendaciones y se ofrecen máximas, sentencias, etc. relativas a la moral y la conducta que los alumnos deben acatar para aprender a ser ciudadanos responsables, trabajadores, honrados, saludables...: "El hombre que bebe alcohol daña su salud", "El ahorro es la base de la fortuna" (p. 91), etc.;

b) los ejercicios, textos de lectura, ejemplos, imágenes etc. que recurren a fuentes literarias de contenido patriótico, la mayoría de ellas pertenecientes a autores uruguayos (Juana de Ibarborou, Carlos Reyles, etc.) o de otros países hispanoamericanos (Germán Berdiales), así como a fuentes pictóricas de artistas uruguayos (José Cúneo);

c) Las alusiones políticas a los héroes libertadores (Artigas, Bolívar, San Martín) o a otros símbolos nacionales (la bandera o el himno uruguayos);

d) las referencias geográficas (el río Negro, el río Cuareim, etc.), geopolíticas ("Montevideo es la capital de la República Oriental del Uruguay", p. 12) y sociales ("Nuestro país recibe a todos los hombres del mundo que se aproximan a su suelo en busca de paz [...]", p. 115);

e) y otros elementos autóctonos (nombres de plantas, objetos, peculiaridades climáticas, etc.) que sirven para ubicar contextualmente la obra, además de insistir en algunos de los rasgos propios e identitarios del país en que aquella se publica.

Este manual ortográfico es un eslabón más de una serie de textos escolares que en la historia de los dos últimos siglos de Uruguay han tratado de salvar la idiosincrasia del país (un país en continuo e intenso proceso de recepción de inmigrados) con la homogeneización de la cultura (priorizando la exaltación de lo autóctono) y la propagación de sus contenidos (lingüísticos y extralingüísticos) entre el mayor número posible de ciudadanos de todas las clases sociales, cuyo sistema de valores y comportamiento también pretendía regular.

Con lo dicho hasta aquí parece confirmarse la necesidad de la existencia de una subdisciplina lingüística provisionalmente llamada Etnortografía (denominación construida por analogía con la Etnogramática y Etnolexicografía), o Socio-Etnortografía (v. Calero Vaquera, 2010) y que podemos definir así:

Disciplina de carácter metalingüístico que se ocupa de analizar el modo como la ideología, las costumbres, las creencias, las experiencias, los comportamientos, etc. de una determinada sociedad quedan reflejados, con una finalidad didáctica, patriótica, moralizante, etc., en los textos ortográficos, especialmente en aquellas secciones complementarias a los contenidos puramente teóricos como puedan ser los ejemplos, ejercicios, ilustraciones...

En conclusión, tanto la Etnolexicografía, como la Etnogramática y la Etnortografía podrían considerarse materias de carácter metalingüístico que formarían parte del ámbito que se viene denominando actualmente Glotopolítica, esto es, el "campo que estudia las políticas lingüísticas y responde a demandas sociales respecto del planeamiento del lenguaje” (Narvaja, 2008: 11); o, por expresarlo con las mismas palabras de quienes propusieron el término con esta acepción: 
[Le terme glottopolitique] Il désigne les diverses approches qu'une société a de l'action sur le langage, qu'elle en soit ou non consciente: aussi bien la langue, quand la société légifère sur les statuts réciproques du français et des langues minoritaires par exemple; la parole, quand elle réprime tel emploi chez tel ou tel; le discours, quand l'école fait de la production de tel type de texte matière à examen: Glottopolitique est nécessaire pour englober tous les faits de langage où l'action de la société revêt la forme du politique (Guespin y Marcellesi, 1986: 5).

En esquema (fig. 2):

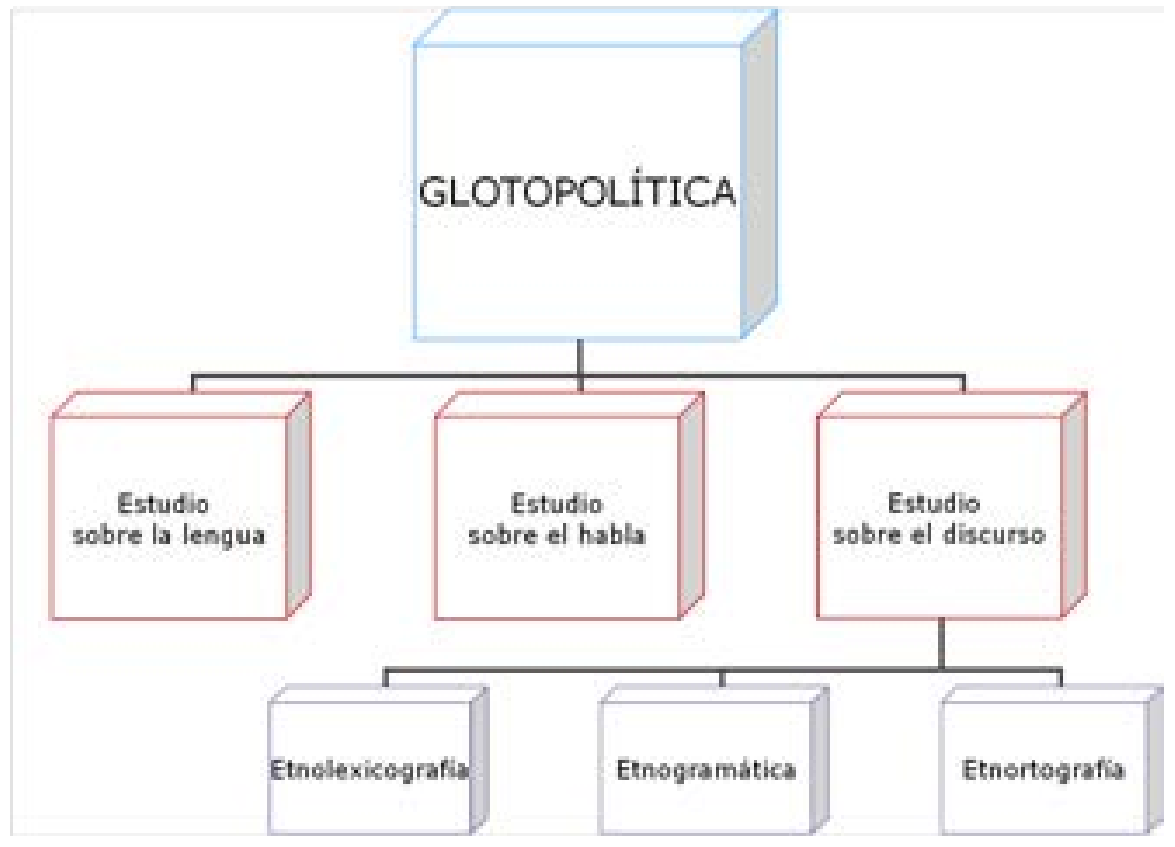

Fig. 2.- La Glotopolítica y sus ámbitos de estudio (con nuestra propuesta de subdisciplinas en los Estudios sobre el discurso) [Elaboración propia] 


\section{Bibliografía}

Ahumada Lara, Ignacio (ed.) (2006), Diccionario bibliográfico de la metalexicografía del español (Orígenes-año 2000), Jaén, Universidad de Jaén (Seminario de Lexicografía Hispánica).

Bacon, Francis (1984 [1620]), Novum organum, Madrid, Sarpe. [Título original: Novum organum, sive indicia vera de interpretatione naturae et regni hominis, 1620. Traducción al español de Cristóbal Litrán.]

Blecua Perdices, José Manuel (1990), “Diccionario y enunciación”, en Profesor Francisco Marsá: jornadas de Filología, Barcelona, Universidad de Barcelona, p. 61-74.

Calero Vaquera, María Luisa (2004), "Métodos de enseñanza gramatical en la tradición: propuesta de nueva disciplina”, en C. Corrales Zumbado, J. Dorta Luis, D. Corbella Díaz, A. N. Torres González, F. M. Plaza Picón, L. Izquierdo Guzmán, M. A. Martín Díaz, J. Medina López y B. Hernández Díaz (eds.), Nuevas aportaciones a la historiografía lingüística (Actas del IV Congreso Internacional de la SEHL), Madrid, Arco/Libros, vol. I, p. 317-326.

Calero Vaquera, María Luisa (2008), “Análisis lógico y análisis gramatical en la tradición española: hacia una (r)evolución de la sintaxis”, en Marina Maquieira y María Dolores Martínez Gavilán (eds.), Gramma-Temas 3 : España y Portugal en la tradición gramatical, León, Publicaciones Universidad de León,, p. 11-42.

Calero Vaquera, María Luisa (2010), "Ideología y discurso lingüístico: la Etnortografía como subdisciplina de la Glotopolítica”, Boletín de Filología, vol. 45, n² 2, p. 31-48.

Casares, Julio (1992), Introducción a la lexicografía moderna, $3^{a}$ ed., Madrid, CSIC. [1ªd., 1950.]

Comellas García-Llera, José Luis (1991), “El ciclo revolucionario de 1820 y la idea de Europa”, Revista de Historia Contemporánea, n5, p. 7-32.

Condillac, Étienne Bonnot, Abbé de (1746), Essai sur l'origine des connoissances humaines. Ouvrage où l'on réduit à un seul principe tout ce qui concerne l'entendement humain, Premiere [-seconde] partie, Amsterdam, Chez Pierre Mortier.

Condillac, Étienne Bonnot, Abbé de (1789), Cours d'étude pour l'instruction du Prince de Parme, t. I: Grammaire, Genève/Avignon, Chez Fr. Dufart/Chez Joly. [1ª ed., 1775.]

Coseriu, Eugenio (1981), "La socio- y la etnolingüística: sus fundamentos y sus tareas”, Anuario de Letras, n' XIX, p. 5-29.

Destutt, Antoine Louis Claude, Comte de Tracy (1970), Eléments d'idéologie. Seconde partie: Grammaire, Paris, Vrin. [1ªd., 1803.]

Descartes, René (1637), Discours de la méthode pour bien conduire sa raison, et chercher la vérité dans les sciences. Plus la Dioptrique, les Météores et la Géometrie, [Paris], De l'Imprimerie de lan Maire.

Dubois, Jean y Claude Dubois (1971), Introduction à la lexicographie: le dictionnaire, Paris, Larousse. 
Durkheim, Émile (1895), Les Règles de la méthode sociologique, Paris, ancienne librairie Germer Baillière et $C^{i e}$, Félix Alcan, éd.

Eagleton, Terry (1997), Ideología: una introducción, Barcelona, Paidós. [Título original : Ideology : an introduction, 1991. Traducción de Jorge Vigil Rubio.]

Eschbach, Achim (1986), “Notes sur la 'Note sur l'influence des signes' de Maine de Biran”, en Winfried Busse y Jürgen Trabant (eds.), Les Idéologues: sémiotique, théories et politiques linguistiques pendant la Révolution française, Amsterdam/Philadelphia, John Benjamins, p. 59-72.

Forgas Berdet, Esther (1996), “Lengua, sociedad y diccionario: la ideología”, en Esther Forgas (ed.), Léxico y diccionario, Tarragona, Universitat Rovira i Virgili, Departament de Filologies Romàniques, p. 71-90.

Forgas Berdet, Esther (2001), "Mujer y diccionario: lo femenino en los ejemplos lexicográficos", Hispanista (Revista electrónica de los hispanistas de Brasil), vol. II, n5, disponible en http://www. hispanista.com.br/artigos\%20autores\%20e\%20pdfs/artigo48esp.htm. [Sitio consultado el 15 de diciembre de 2018.]

García, Nicasio H. (1947), Plan concéntrico de ortografía. Curso elemental, $2^{2}$ ed., Montevideo, Libreros-Editores A. Monteverde y Cía.

García de la Madrid, Miguel (2008), La Ideología o Tratado de las Ideas y de sus Signos, Barcelona, Antonio Brusi. [Edición de Julia Fernández Tellechea, Universidad de Navarra, $1^{a}$ ed., 1820.]

Guespin, Louis y Jean-Baptiste Marcellesi (1986), "Pour la glottopolitique”, Langages, n 83, p. 5-34.

Hassler, Gerda (1990), "Los 'ideólogos' franceses y la continuidad de sus temas lingüísticos en el pensamiento español al inicio del siglo XIX”, Glosa, nº 1, p. 135-156.

Hobsbawm, Eric (2007), La era del capital, 1848-1875, Barcelona, Crítica. [Título original: The Age of Capital: 1848-1875, 1975. Traducción de Carlo A. Caranci y Ángel García Fluixá.]

Lakoff, Georgey Mark Johnson (1986), Metáforas de la vida cotidiana, Madrid, Cátedra. [Título original: Methafors We Live By, University of Chicago Press, 1980. Traducción de Carmen González Marín.]

Lamo de Espinosa, Emilio, José María González García y Cristóbal Torres Albero (1994), La sociología del conocimiento y de la ciencia, Madrid, Alianza Editorial.

Lenk, Kurt (2011 [1961]), El concepto de ideología: comentario crítico y selección sistemática de textos, Buenos Aires, Amorrortu editores. [Título original: Ideologie. Ideologiekritik und Wissenssoziologie, 1961. Traducción de José Luis Etcheverry.]

Lledó, Eulalia, María Ángeles Calero y Esther Forgas (ed.) (2004), De mujeres y diccionarios: evolución de lo femenino en la $22^{\circ}$ edición del DRAE, Madrid, Instituto de la Mujer (Ministerio de Trabajo y Asuntos Sociales).

Locke, John (1690), An essay concerning humane understanding, London, Printed for Tho. Basset, and sold by Edw. Mory. 
Martinell, Montserrat (1984), "Gramática y moral”, Revista Española de Lingüística, nº 14:1, p. 168-169.

Marx, Karl (1867), Das Kapital. Kritik der politischen Oekonomie. Ester Band. Buch I: Der produktionsprocess des Kapitals, Hamburg, Verlag von Otto Meissner.

Medina Guerra, Antonia María (ed.) (2003), Lexicografía española, Barcelona, Ariel Lingüística.

Miguel, Raimundo de (1882), Gramática hispano-latina, teórico-práctica para el estudio simultáneo de las lenguas latina y castellana comparadas, $21^{2}$ ed., Madrid, A. Jubera.

Moravia, Sergio (1986), "La mauvaise étoile historique des Idéologues", en Winfried Busse, y Jürgen Trabant (eds.), Les Idéologues. Sémiotique, théories et politiques linguistiques pendant la Révolution française, Amsterdam/Philadelphia, John Benjamins, p. 3-6.

Narvaja de Arnoux, Elvira (2008), Los discursos sobre la nación y el lenguaje en la formación del Estado (Chile, 1842-1862): estudio glotopolítico, Buenos Aires, Santiago Arcos editor.

Palmer, Gary B. (2000), Lingüística cultural, Madrid, Alianza Editorial. [Título original: Toward a theory of Cultural Linguistics, 1996. Traducción de Enrique Bernárdez.]

Pascual, José Antonio y María del Carmen Olaguíbel (1992), "Ideología y diccionario", en Ignacio Ahumada (ed.), Diccionarios españoles: contenidos y aplicaciones (Lecciones del I Seminario de Lexicografía Hispánica, Jaén, 21-24 de enero de 1991), Jaén, Casa Editora El Estudiante, p. 73-89.

Pêcheux, Michel (2016 [1975]), Las verdades evidentes: lingüística, semántica, filosofía, Buenos Aires, Ediciones del CCC Centro Cultural de la Cooperación Floreal Gorini. [Título original: Les Vérités de la Palice: linguistique, sémantique, philosophie, Paris, François Maspero, 1975. Traducción de Mara Glozman, Pedro Karczmarczyk, Guadalupe Marando y Margarita Martínez.]

Pérez Cuadrado, Cosme (1946), Curso superior de Gramática española simbólica e intuitiva, $2^{2}$ ed., Madrid, Ediciones Atlas.

Pérez Hernández, Francisco Javier (2000), Diccionarios, discursos etnográficos, universos léxicos: propuestas teóricas para la comprensión cultural de los diccionarios, Caracas, Fundación Centro Estudios Latinoamericanos Rómulo Gallegos/Universidad Católica Andrés Bello.

Picavet, François (1971), Essai sur l'histoire des idées et des théories scientifiques, philosophiques, religieuses, etc. en France depuis 1789, New York, Burt Franklin. [1 ed., 1891.]

Real Academia Española (2015), Diccionario de la lengua española (DEL), ed. del Tricentenario, $23^{2}$ ed., versión electrónica 23.1., disponible en: http://www.rae.es/obras-academicas/diccionarios/diccionario-de-la-lengua-espanola. [Sitio consultado el 26 de febrero de 2018.]

Ricken, Ulrich (1986), "Les ideólogues et la sensation transformée”, en Winfried Busse y Jürgen Trabant (eds.), Les Idéologues. Sémiotique, théories et politiques linguistiques pendant la Révolution française, Amsterdam/Philadelphia, John Benjamins , p. 19-43.

Rodríguez Barcia, Susana (2008), La realidad relativa: evolución ideológica en el trabajo lexicográfico de la Real Academia Española (1726-2006), Vigo, Servizo de Publicacións. 
Rodríguez Paniagua, José María (1972), Marx y el problema de la ideología, Madrid, Editorial Tecnos.

Sánchez-Blanco, Francisco (2007), La ilustración goyesca: la cultura en España durante el reinado de Carlos IV (1788-1808), Madrid, Consejo Superior de Investigaciones Científicas / Centro de Estudios Políticos y Constitucionales.

Sapir, Edward (1971 [1921]), El lenguaje. Introducción al estudio del habla, $3^{a}$ reimpr. de la $1^{a}$ ed. española (1954), México, Fondo de Cultura Económica. [Título original: Language: An Introduction to the Study of Speech, 1921. Traducción de Margit y Antonio Alatorre.]

Saussure, Ferdinand de (1916), Cours de linguistique générale, ed. por Charles Bally y Albert Sechehaye, Lausanne/Paris, Payot et $C^{i e}$.

Schlieben-Lange, Brigitte, Marco Bergandi, Roland Bernecker, Hans-Dieter Dräxler, llona Pabsty Elisabeth Volck-Duffy (eds.) (1989-1994), Europäische Sprachwissenschaft um 1800. Methodologische und historiographische Beiträge zum Umkreis der 'idéologie', Münster, Nodus Publikationen.

Seco, Manuel (1987), Estudios de lexicografía española, Madrid, Paraninfo.

Swiggers, Pierre y Nico Lioce (2003), "Grammaire, réalité et image du monde dans les Leys d’Amors", en Rossana Castano, Saverio Guida y Fortunata Latella (eds.), Scène, évolution, sort de la langue et de la littérature d'oc tome I, Roma, Viella, p. 675-684.

Van Dijk, Teun A. (1999), Ideología. Un enfoque multidisciplinario, Barcelona, Gedisa. [Título original: Ideology: A multidisciplinary approch, 1998. Traducción de Lucrecia Berrone de Blanco.]

Volóshinov, Valentin N. (1992 [1929]), El marxismo y la filosofía del lenguaje, prólogo de I. M. Zavala, Madrid, Alianza. [Título original: Marksizm i filosófiya yazyká, 1929. Traducción de Tatiana Bubnova].

Zollna, Isabel (2004), "La ilustración francesa y su repercusión en las teorías lingüísticas españolas: la influencia de los 'ideólogos'”, en Jesús Cañas y Sabine Schmitz (eds.), Aufklärung: Literatura y cultura del siglo xviii en la Europa occidental y meridional. Estudios dedicados a Hans-Joachim Lope, Frankfurt, Peter Lang, p. 263-275. 